\author{
Accelerator Department: \\ BROOKHAVEN NATIONAL IABORATORY \\ Associated·Universities, Inc. \\ Upton; L.I., N.Y. \\ AGS DIVISION TECHNICAI, NOTE \\ No. 50 \\ J.C. Schuchman \\ Apri1 5, 1968:
}

\title{
AERO VAC AVA-1 RESIDUAL GAS ANALYZER OPERATING PROCEDURE: AND GENERAL NOTES ON MASS : SPECTROMETRY
}

Operate only if pressure at $F-7$ is below $1 \times 10^{-4}$ Torr.

1. Switch on power to recorder, control and remote amplifier.

2. a) Wait for equipment to stabilize (2 minutes) and switch on filament. NOTE: When filament is turned:on or off, the emission control should first be turned down to a low: value.

b).. Set filament current to 8.0 microampere. NOTE: This current will change with system pressure changes and should be adjusted as required.

3. Select desired mass range: : Low 2-11 ( $\mathrm{H}_{2}, \mathrm{He}$ )

$$
\text { High } \left.12-70 \text { ( } \mathrm{CH}-, \mathrm{H}_{2} \mathrm{O}, \mathrm{N}_{2} \mathrm{~A}\right)
$$

NOTE: When switching from one range to another, allow $30 \mathrm{sec}$ for magnet shunt: to change position, thus changing ranges:

4. Select Pressure Range: $5 \times 10^{-9 /-11}$ Torr

$$
\begin{aligned}
& 5 \times 10^{-7 /-9} \text { Torr } \\
& \text { (approximate partial pressures may be read directly off chart) }
\end{aligned}
$$

5. To record residual gas spectrum:

a. Set recorder chart speed to 360 in/hr.

b. Switch on toggle switch for automatic scan.

System will: continue to rescan until switch is turned off.

6... To monitor a single mass peak; manually set the ion volts control to the proper voltage and start the irecorder."

NOTES 1.: This residual gas analyzer can be operated while the AGS is operating, however, the noise pick-up will obscure most of the signal and much of the scan will be lost. It is recommended that the instrument be operated while the AGS is off. 
2. The recorder is a three decade log-linear model. . Its purpose is to expand the smaller peaks thus increasing sensitivity. This point should be kept in mind when comparing peak heights.

3. To find a particular peak set voltage as follows:

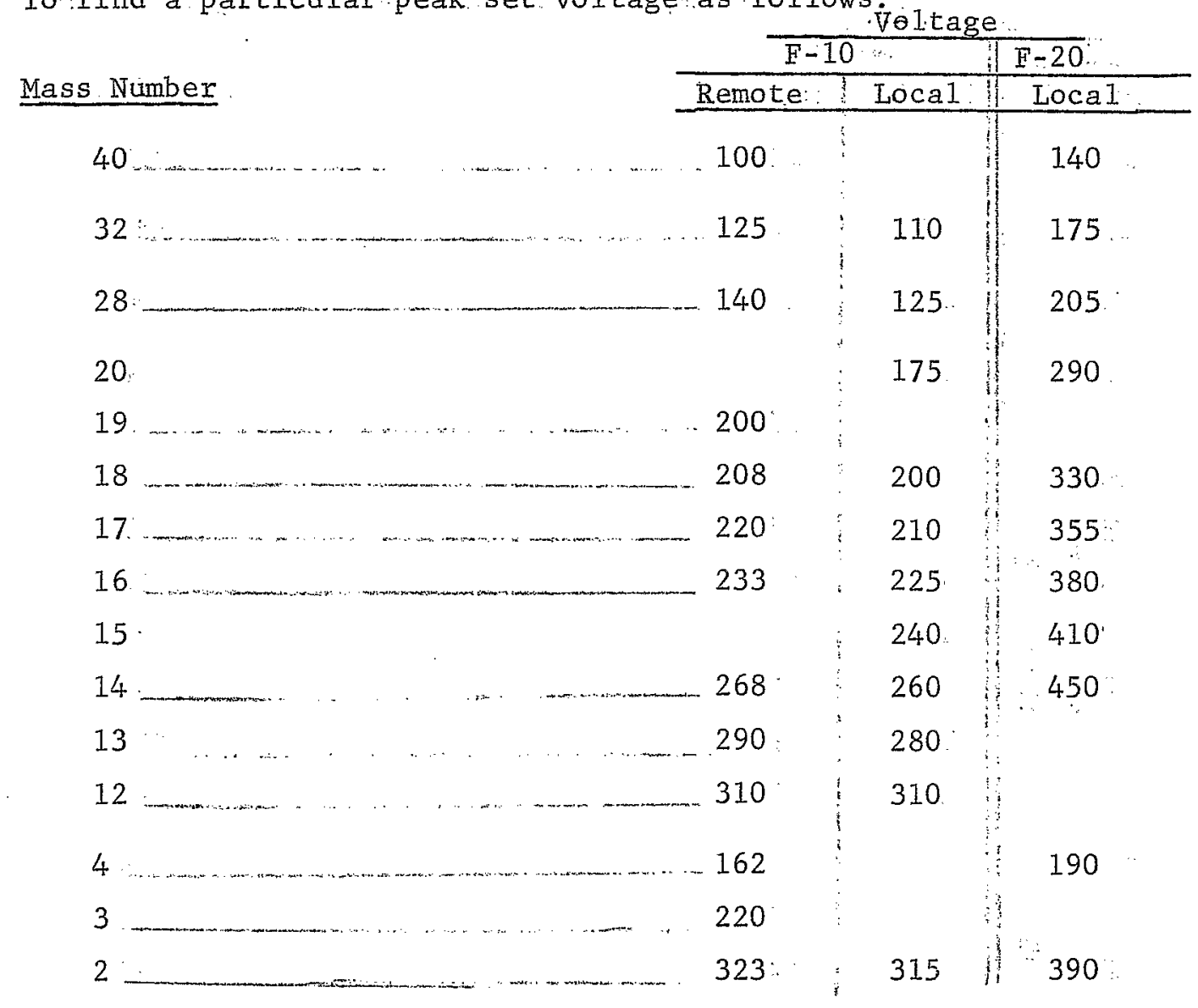




\section{Table of Contents}

I. Spectroscopy

PI. Calibration of AVA-1

III. Typical Mass :Spectra:

Fig. 1 F-10 Box, under vacuum for 2 hours; high mass wange, scale $10^{-7 /-9}$.

Fig. 2 F-10 Box, under vacuum for 2 hours, high mass range, scale $10^{-9 /-11}$.

Fig. 3 F-10 Box under vacuum for 2 hours, low mass range, scale $10^{-9 /-11}$

Fig, 4.. Same as Fig. 3. with zero lowered.

Fig. 5. F-10 Box under vacuum for 8 days, high mass range, scale $10^{-7 / 2}-9$

Fig. 6 F-10 Box under vacuum"for 8 days, high mass range, scale $10^{-9 /-11}$.

Fig. 7 F-10 Box under vacuum for 8 days, low mass range, scale 10-9/-11.

Fig: 8 F-10 Box; AGS accelerated beam.

Fig. 9 ...Typical air leak (taken on Veeco GA-3).

Fig. 10 Typical water leak (taken on Veeco GA-3): :

Fig. 11 F-10 Box typical scan after one day of pumping(linear scale chart

Fig. 12 F-20 Target Area, air leak (1inear scale chart paper)

IV. Leak Detection 


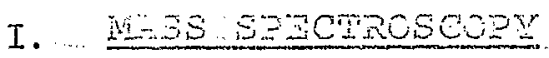

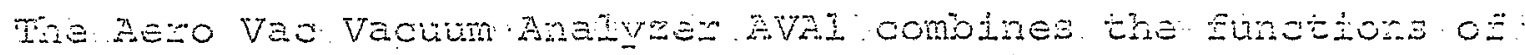

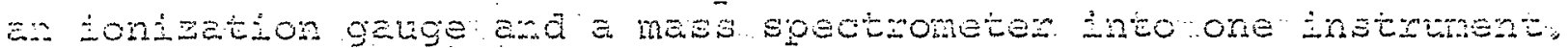

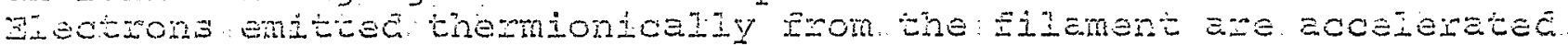

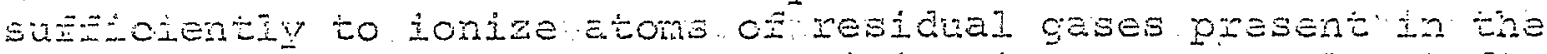
vacum syotem. The resulting positive ions are acceierated and Focused Com a tube. The ion then pass through a magnetic Ei wisere the amount of defuection depencs on the ion velocity. Snejging From the magnetic fierd; jons ot the same mass are Eodused on one ootnt down the tube, a point which dizfers from the points of foeus for ions of other masses.

Stroe the ion velocity depends on the acceierating electrio Fieid. ions of any mass desized witin the range oz the instrument cen je Focused on the collectoz at the end of the tube and measured as an electric current. If the acceiereting voltage is inoreased Iineariy, the coliector current wil vary according to

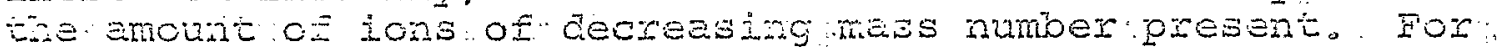
constant magnetic field, the mass specie collected is inverseiy poyorional to the ion accelerating roltage. Conseguently. En X or M-Y plot shows mas mumber varying hyperbolicaliy, not Ineariy:

In anms pectroneter sensitivity and resolition are tre

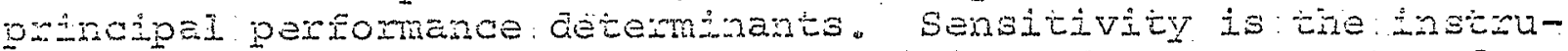
man's ability to detect smaz quantities of ges present anc cepends on the efficiency with which ions are ioned Foovsed, and ocilected. Resolution is the efFectiveness with which

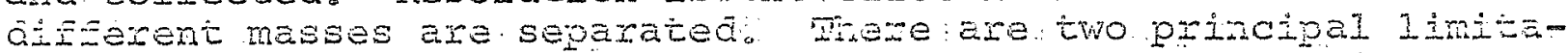
tions on Iesolution. one is that the ions have a distribution of.Velocities prior to acceleration. Consequenty the veiocity oz a ions of a given mass is not the wame when they are defiectea and separated by the magnetid field. However, the greater the acceletation by the electric field the smalierwil be the gercentage variation in velocities of ions of a given mass The cthe: initation is that the percentage separation by mass is min larger Foz. Iow mass numbers than high ones Consequentiy; abojution falis off at high mass numbers. In adition sone

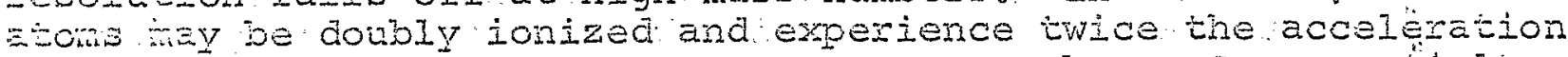
s E sing $+y$ ionized atoms of the same mass number. Scme particles Wiz. be singly-ionized moiecules $(0.9$. N2) and others singlyionized atoms ( $($.9., N). Whese effects are not serious but. mist be considered in. interpreting mass spectra.

Inceroretation of mass spectra requires experience, but is zacilitated by faniliarity. with the pattems produced by comon resodual gases. Typical spectra are included in the Apoendix. 


\section{MASS SPECIE IDENTIFHCATION}

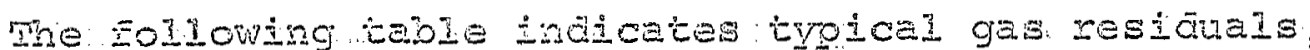
associated with appearnee o mass specie in Vecuun

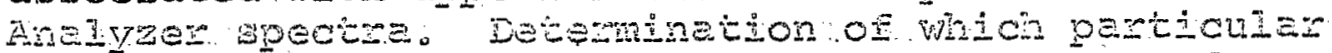
gas u the cause of an tradicaced residue depends on information as: to systen history. appized leaks. type of test specimen, etc. In some cases, gas reaiduals not.13sted may be present.

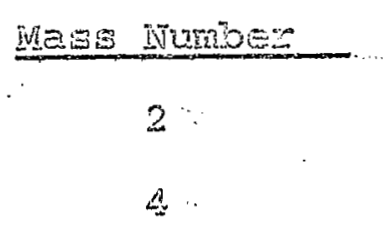

12

13

14

15

56

17

18

19

20

21 .

22

23
Tróael Gas Residual

Fydrogen $\left(\mathrm{Fi}_{2}^{+}\right)$

FeI

Carioon $\left(\mathrm{C}^{+}\right)$

Radical (CF)

Nitrogen $\left(\mathrm{N}^{+2}\right)$

Reaical (CH

$\operatorname{RadicaI}\left(\mathrm{CH}_{3}\right)$

orygen $\left(0^{+}\right)$

Methane $\left(\mathrm{CH}_{4}^{-}\right)$, sulinus $\left(\mathrm{s}^{+}\right)$.

Radical $\left(\mathrm{OH}^{+}\right)$

Water: $\left(\mathrm{H}_{2} \mathrm{O}^{+}\right)$

Fluorine (st), Heavy water (HDO')

Argon $\left(A r^{++}\right)$, Neon $\left(22^{N e^{+}}\right)$

Carbon Dioxide $\left(\mathrm{CO}_{2}^{+\dagger}\right)$

Nieon $\left(22^{\mathrm{Ne} e^{+}}\right)$

Sodium: $\left(\mathrm{Na}^{+}\right)$ 
Ms

24

25

26

27

28

29

30

31

32

33

34

35

36

37

38

39

40

41

42

43

44
Ses:C0ass

Radical (C)

Radical: $\left(\mathrm{C}_{2} \mathrm{~F}^{+}\right)$

$\mathrm{RadicaI}\left(\mathrm{C}_{2} \mathrm{II}_{2}{ }^{+}\right)$

Radical $\left(\mathrm{C}_{2} \mathrm{~F}_{3}^{+}\right)$

Nitrogen $\left(\mathrm{N}_{2}^{+}\right)$.

Carbon inoside $\left(\mathrm{cot}^{+}\right)$

Raaical $\left(\mathrm{C}_{2} \mathrm{E}_{4}^{+}\right)$

Radical $\left(\mathrm{C}_{2} \mathrm{II}^{+}\right)$

Radical $\left(\mathrm{C}_{2}{ }^{+1}{ }^{\dagger}\right)$

Phosphorus $\left(P^{+}\right)$

oxygen $\left(0_{2}^{+}\right)$, sulfur $\left(s^{+}\right)$

Chlorine $\left(35^{\mathrm{Cl}}\right)$

chlorine $\left(37^{\mathrm{Cl}}\right)$

Potassium $\left(K^{+}\right)$

Argon $\left(\mathrm{Ar}^{+}\right)$, Calciun $\left(\mathrm{Ca}^{+}\right)$

Carbon Dioxide: $\left(\mathrm{CO}_{2}^{+}\right)$

Organio compounds and cadicals occur chroughout the spectrum. Niany or these are grouped around nultiples of catbox. (12-1.5:RU, 24-30 ANIU, ecco). 


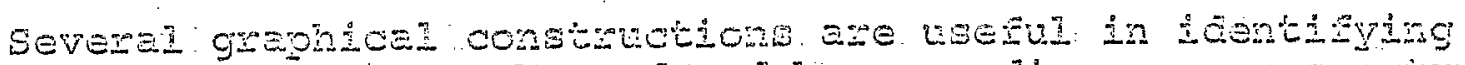
the mes number of a peck produced by peconding a mas apedtun.

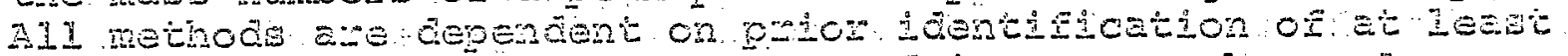

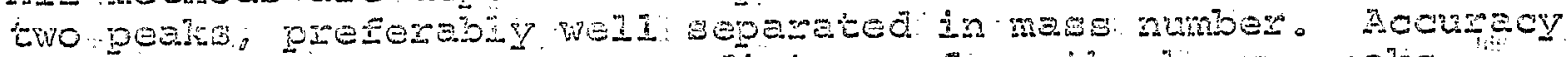

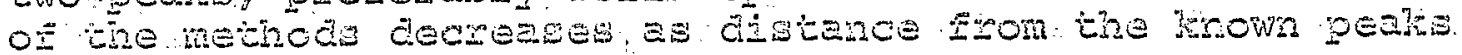

increases.

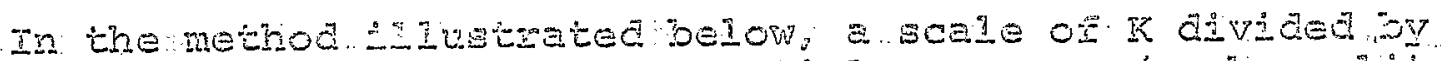
mass number is set up ajong the partal pressure (oeak amplituce)

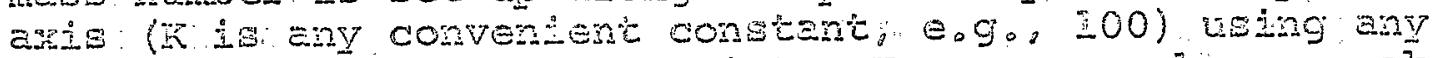
convenient scaie and zexo point. Two or mose known peaks are..

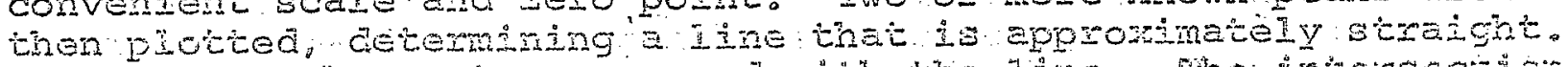

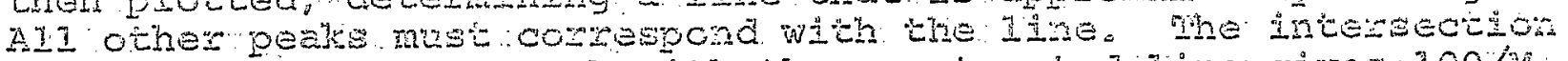
of the center of the peak with the constructed line gives $100 / \mathrm{M}$ read from the scale. Whe mas numoes of the peak is chen 100 divided by the seale reading.

\section{PROCEDUR표:}

1. Set up a seale from 0 to 10 on the sheet on which the: sectirn is tecorded zero may be at any point and ary convenient interval may be used.

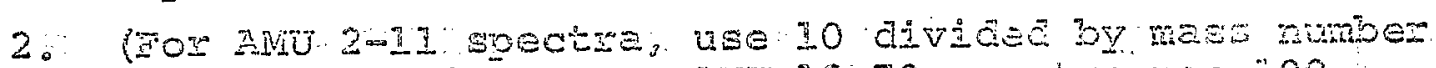

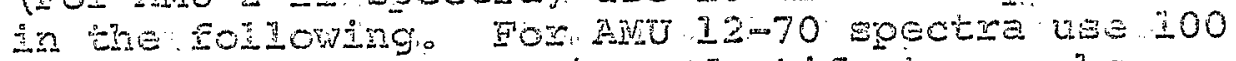
divided by mass muber)。 tdentify two pears. cancria te 100 divida by the mass number for each

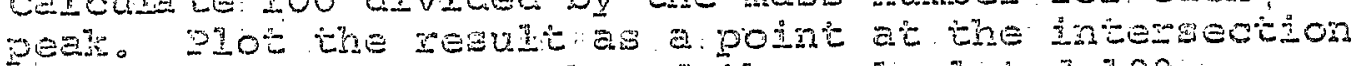
of che ayos of the pear and the calculated 100 dvided by nass amber on the scale set up for each peas. Draw a straight line through the two Loints.

3. To identioy a peat note the intersectionota Ine through the center of the peal and the Ise constructed in 2 above. Read the corresponding value of 100 divided by mas number from the wesie. The mess numer of the pean is the integer neasest 100 divided by bodereading。

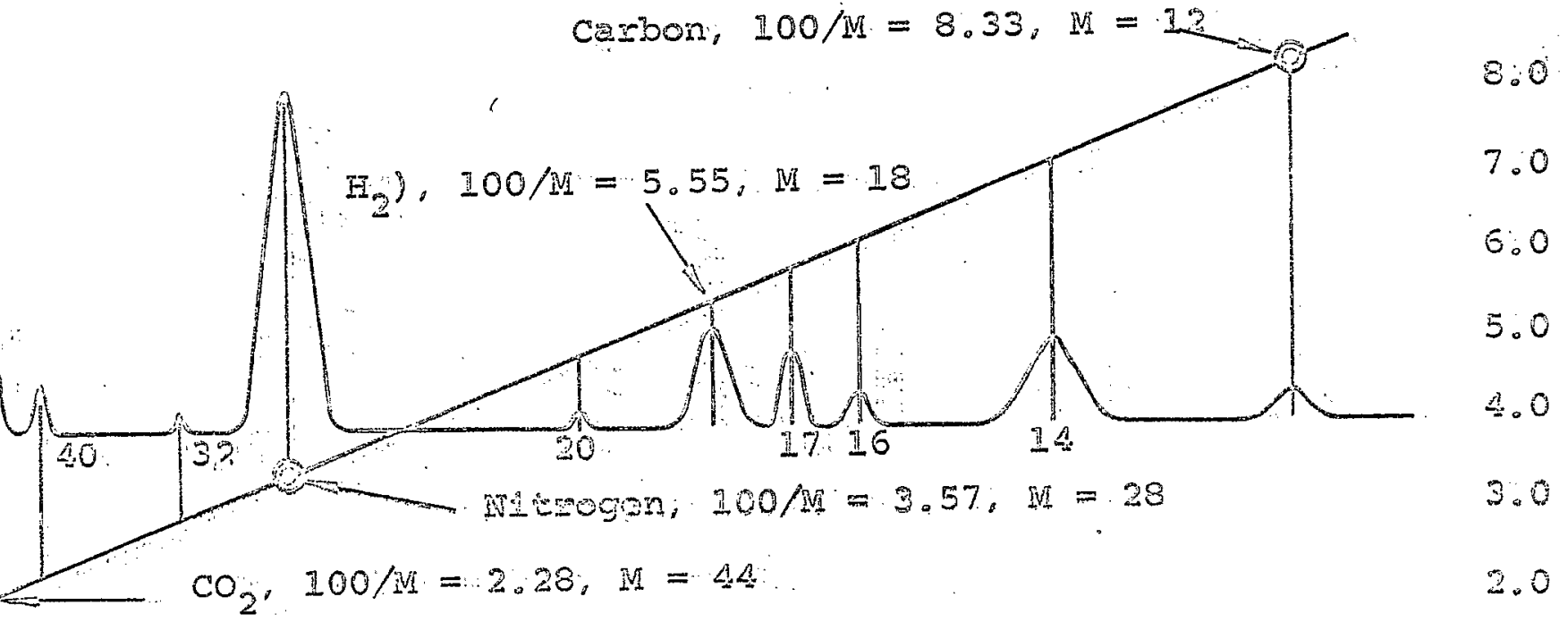


II. CATIBRATION. OF AVA-I

(Aero Vac)

I. Redice syster pressure to $100 \times 10^{-6}$ eorn or lower.

2. Admit the gas to be cailorated, through a leak, so that the total pressure rises at least one decade (e.9:1.0.x. $10-5 \cdot \operatorname{tos})$.

3. Note the total pressure: increase by using an absoite pressure gauge such as a Mcleod Gauge.

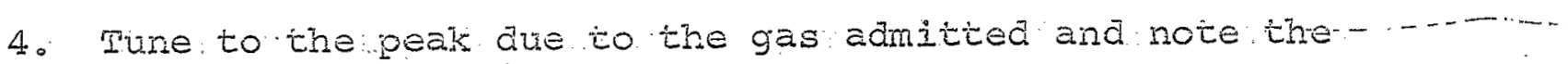
partial pressure incease.

5. Calculate $K=\frac{\text { Dotal }}{\text { Epartal }}$

I. is the calibration constanto

6. If; tor example, nitrogen was used the result might be:

$$
\begin{aligned}
& P_{\text {Gotal }}=1.0 \times 10^{-5} \text { torr } \\
& P_{28}=1.0 \times 10^{-7} \operatorname{tors}
\end{aligned}
$$

Then: $\quad K=\frac{1.0 \times 10^{-5}}{1.0 \times 10^{-7}}=100$

In this example; nitrogen pressure is calculated by multiplying indicated mass 28 partial pressure by 100. 


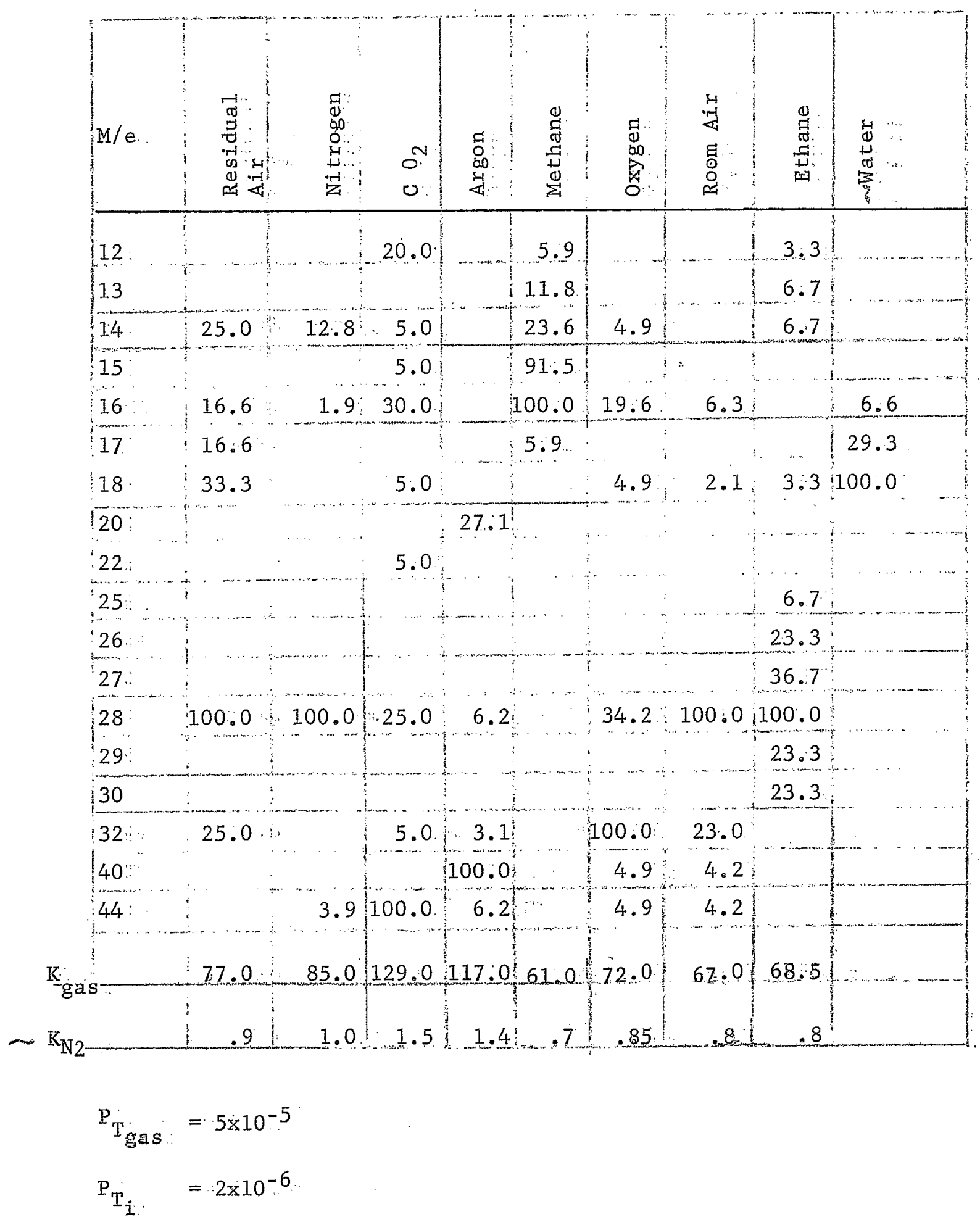

Per R. Lang AIL : 


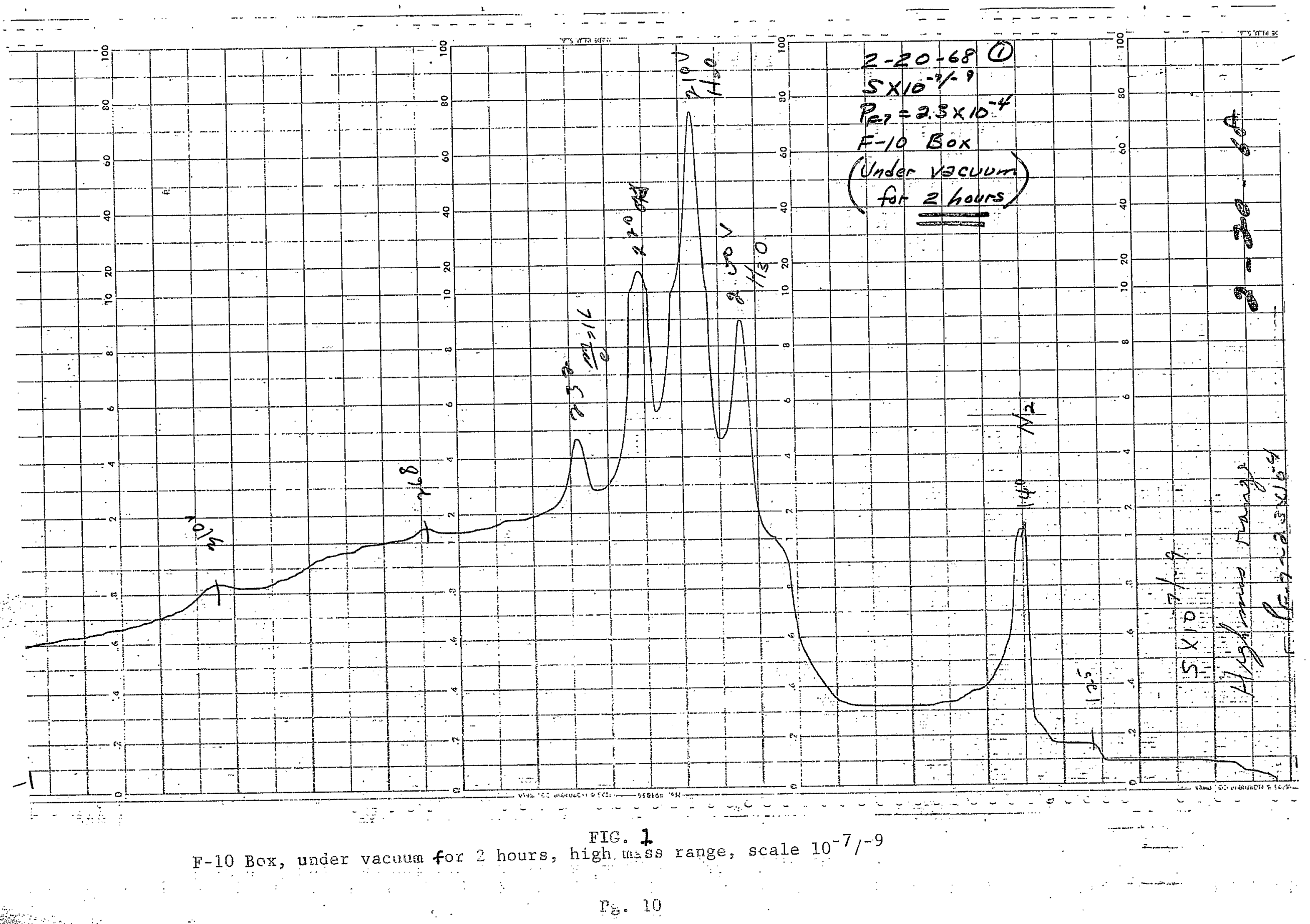




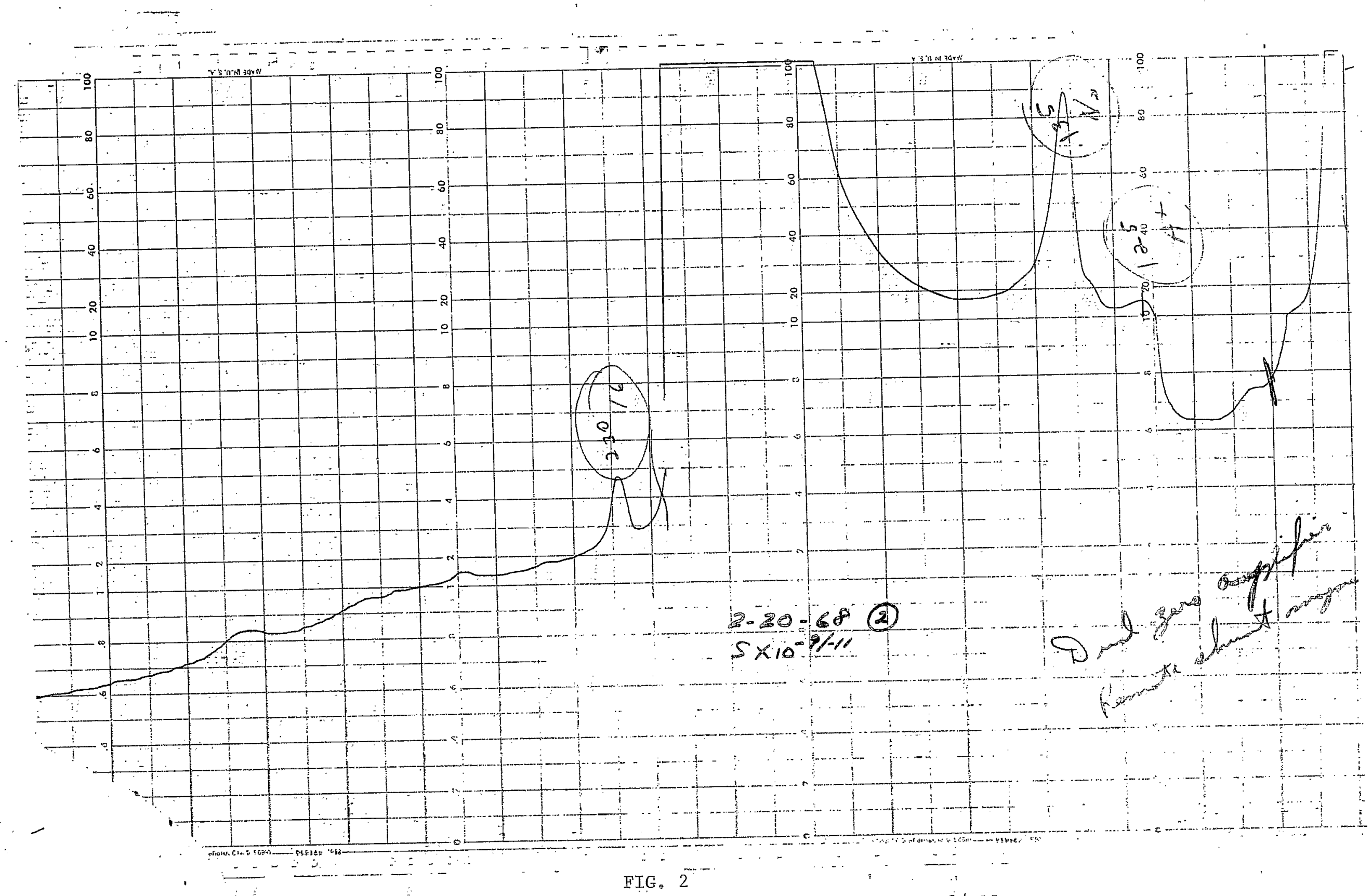

F-10 Box, under vacuum for 2 hours, high mass range, scale 10-9/-11

$\mathrm{Pg}, 11$ 


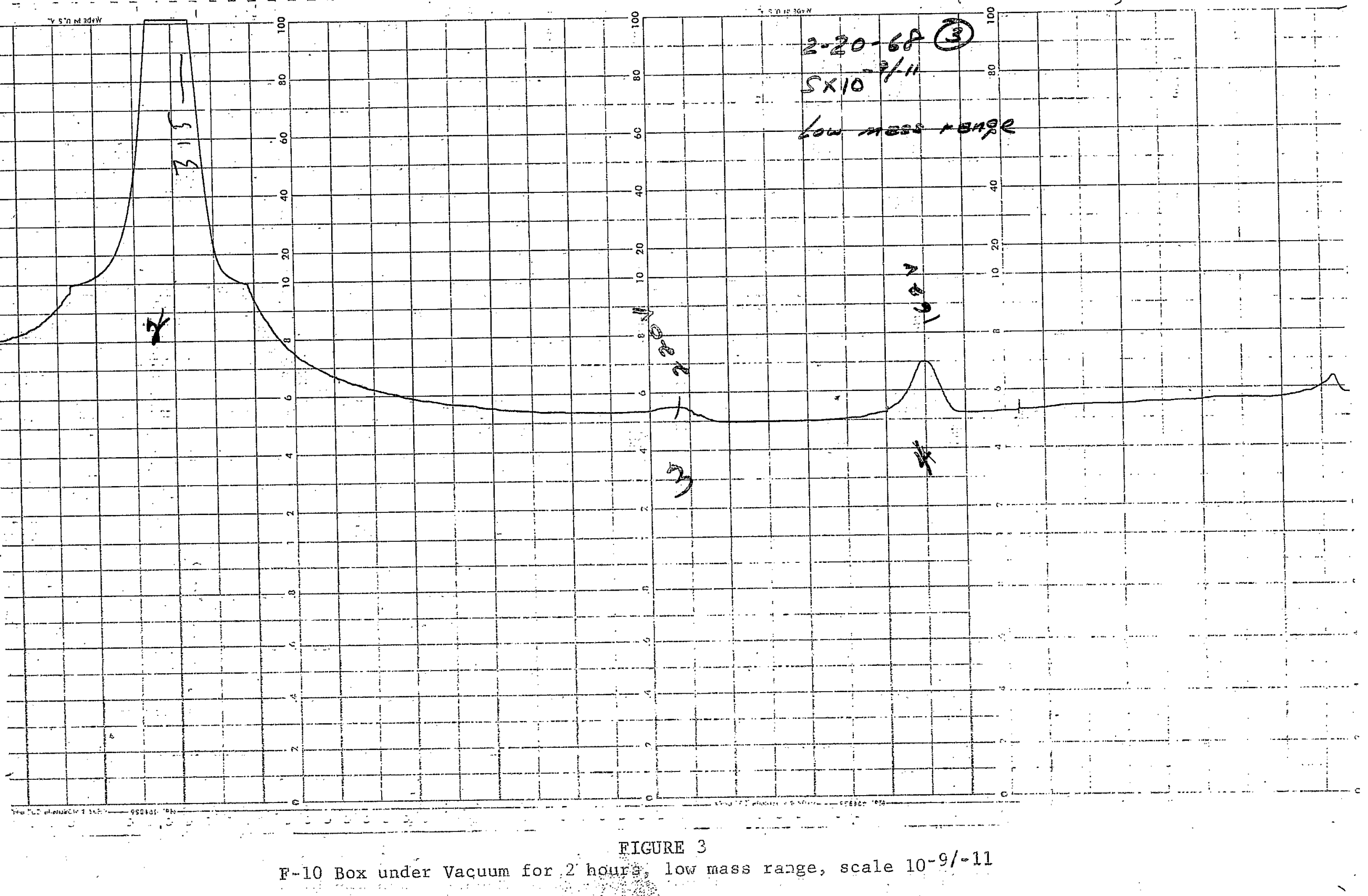




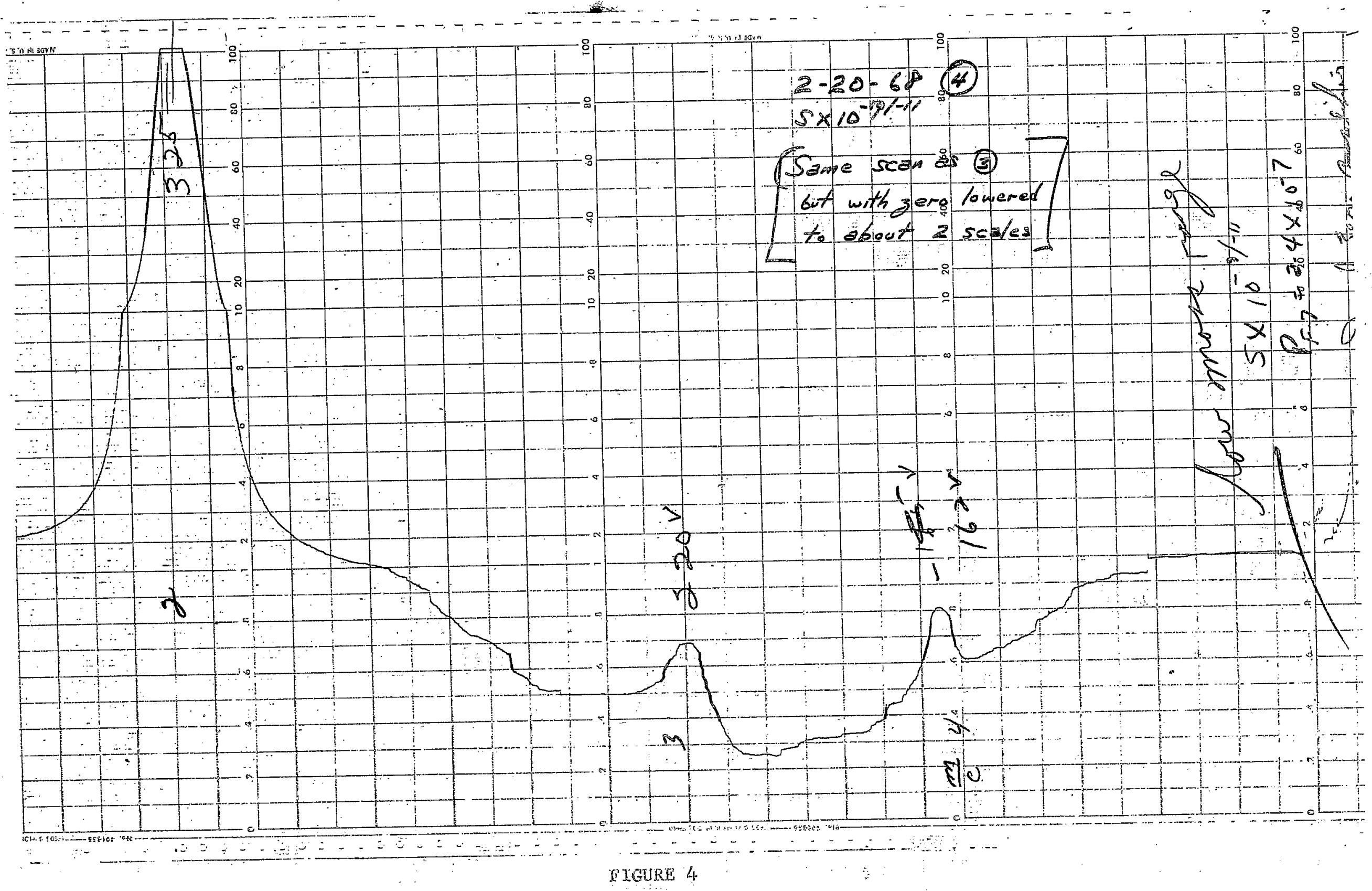

Same as Figure 3 with zero. lowered.

PQ⿱⺈⿻コ一心 13 


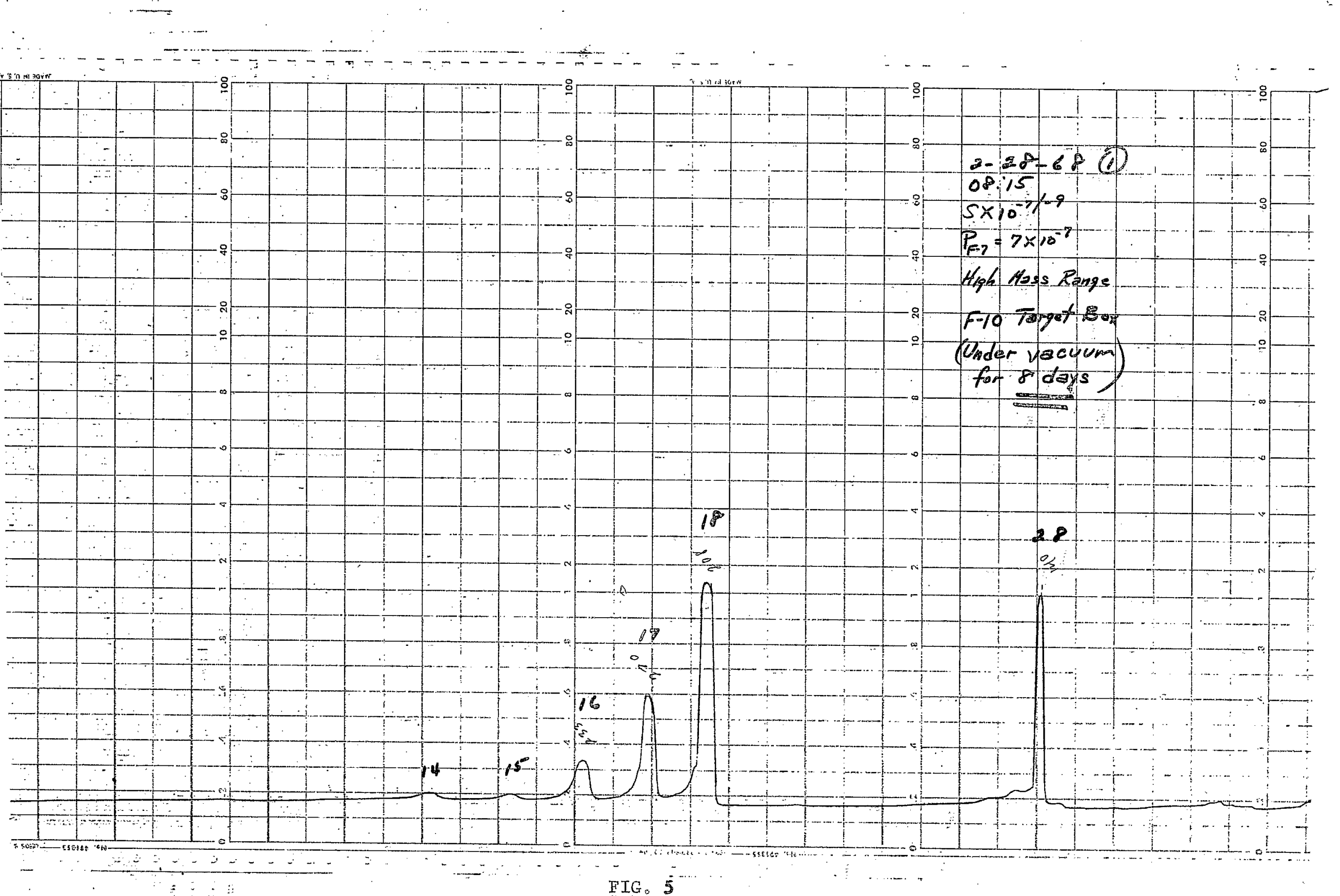

F-10 Dox under vacuum for 8 days igh mass range, scale $10^{-7 /-9}$ 


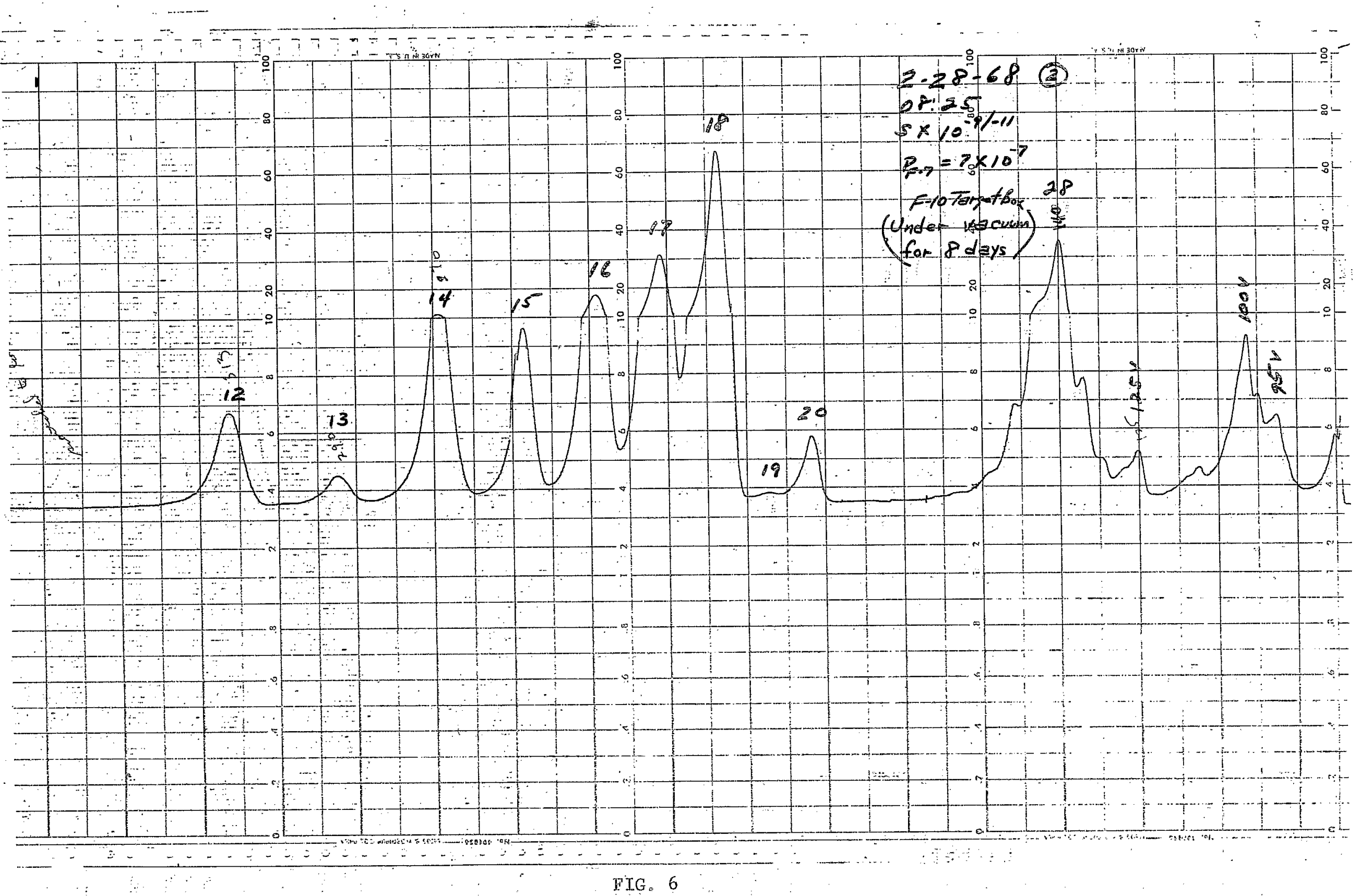

F-10 Box under vacuum for 8 days, high mass range, scale $10-9 /-11$

$\mathrm{Pg} \cdot \quad 15$ 




Typical Air Leak (taken on Veeco GA-3) 


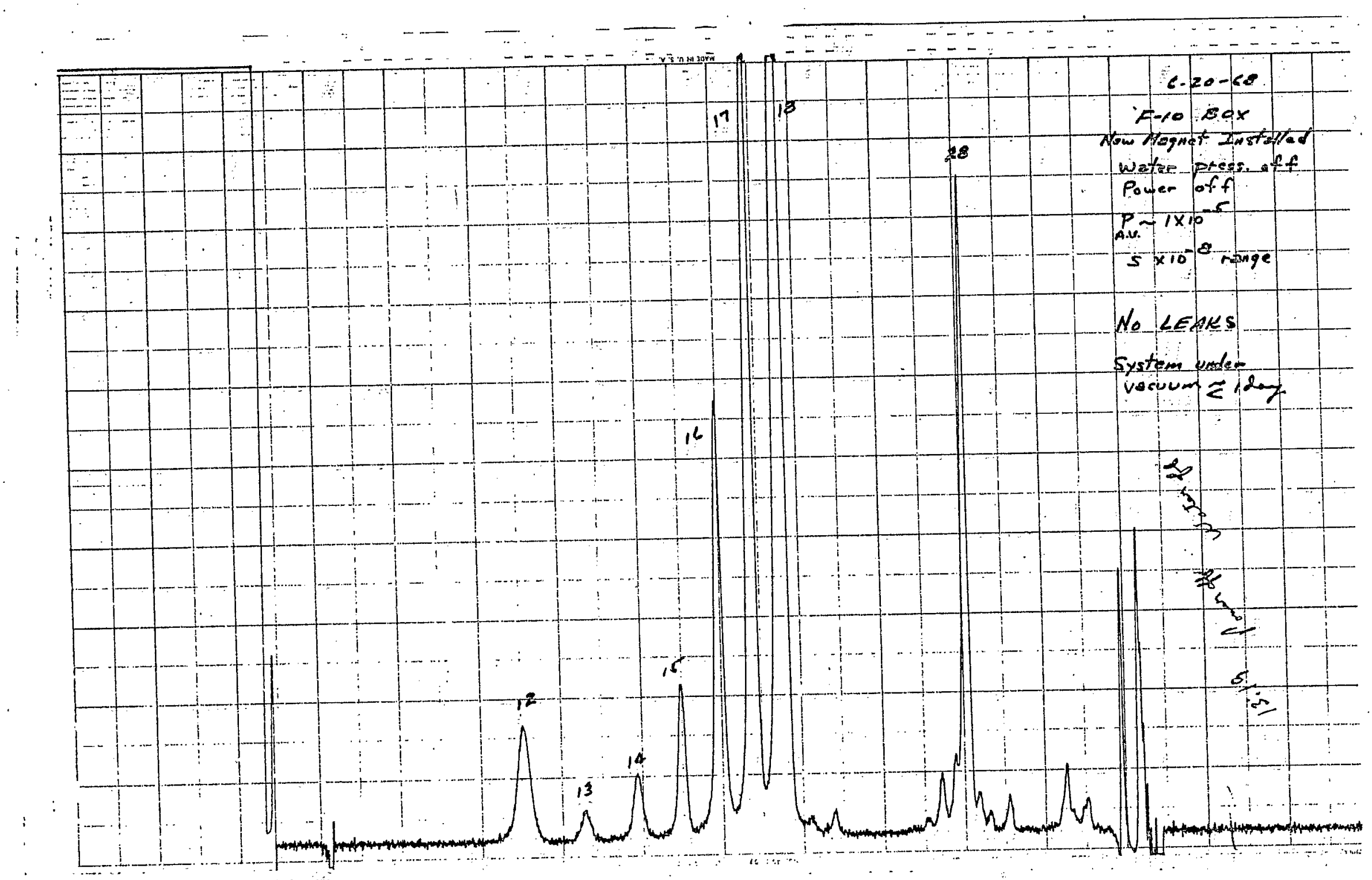

Fig. 11

F-10 Box Typical Scan after One Day of Pumping (linear scale chart paper.) 


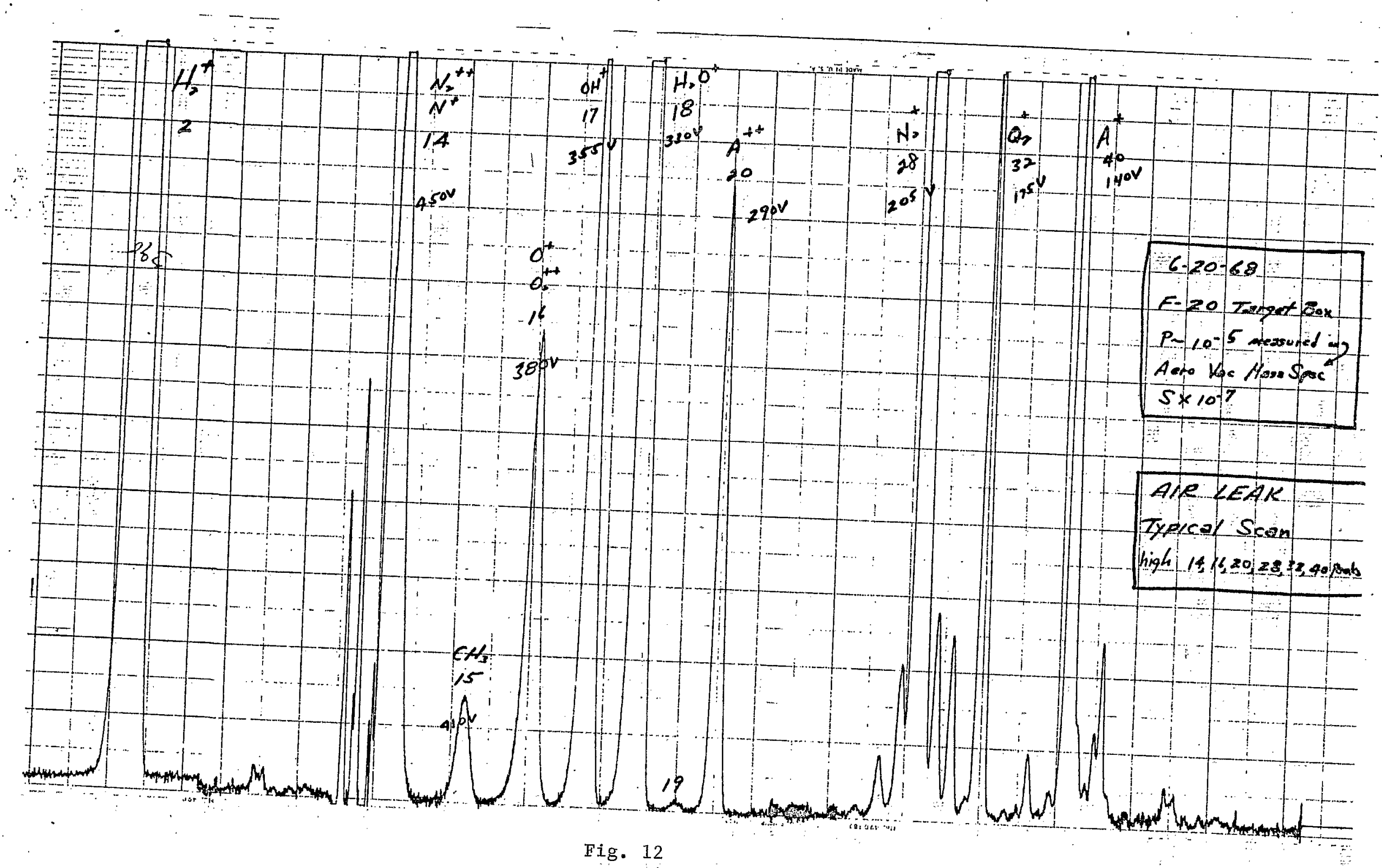

F-20 Target Area, Air Leak (1inear scale chart paper). 


\section{Lear Decection}

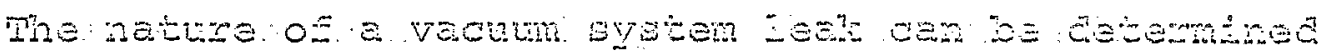

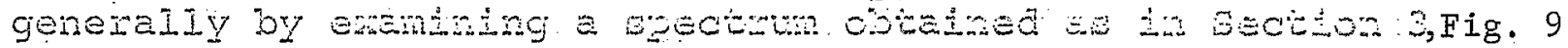

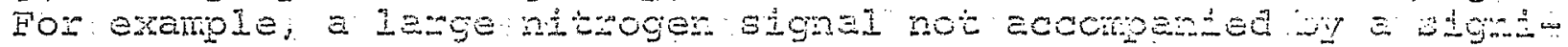

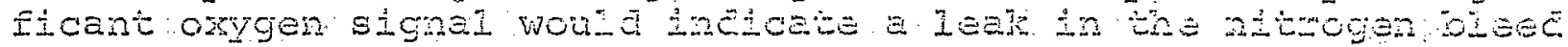
or vent system, whereas the acitional presence o orygen world

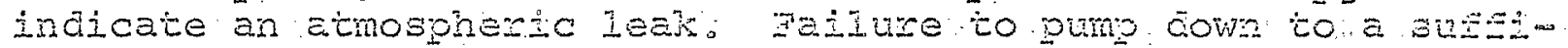
cientiy low pressure may be caused by a híg outgassing ate. Such a zajlure may appear to ba a leak A lange water (AMU is) signal, for example, would probaby indadee high outosesing oz water from paints on other surfades in the epsten.

The indication that an etmosphero leak exists iz

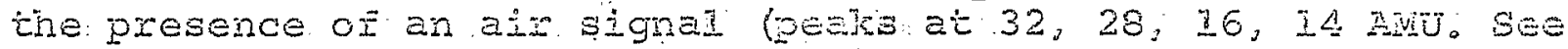
Typical Spectrum - R mined by pabing with a tracer gas. The most comon are in cated below, along. with the indication as the leak is aroroached with the probe gas:

\begin{tabular}{|c|c|c|}
\hline PROSE GAS & PEAX OSSERVED & INDICZTION \\
\hline Hellum (4) & 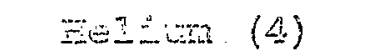 & Inc: \\
\hline Fe1:um ( & $n=2=090 \mathrm{n}$ (28) & Decェ@as \\
\hline Argon $\quad(40)$ & IIf9om $(40)$ & $\begin{array}{l}\text {-acrease } \\
\text { Deqnease }\end{array}$ \\
\hline
\end{tabular}

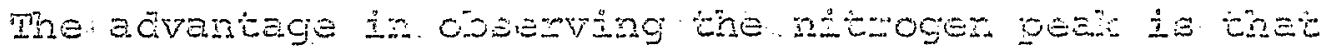

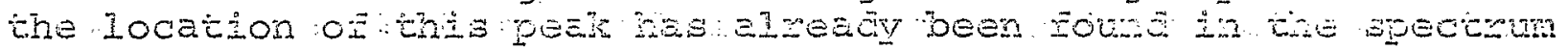
that indicated an air zeak. zagon ha the advartege oE greater

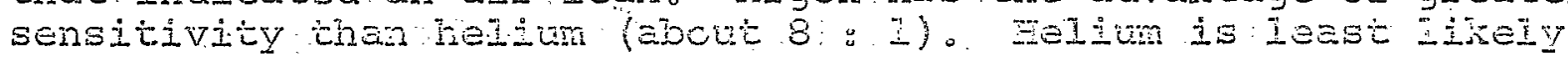
to be confused with other peaks of the same mass rumber.

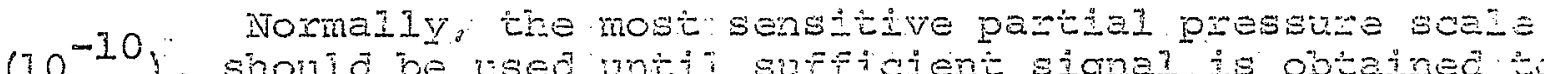

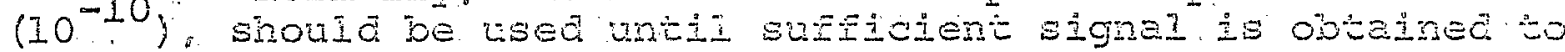

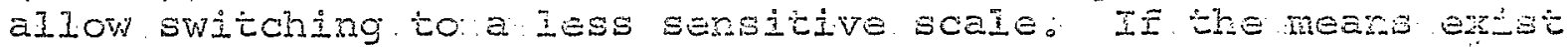
on the vacuum systen being. used, leak test eenstivity can jo increased oy throtting down the pumping speed this has tis disadvantage of increasing. the cine constant, howevew (tine from application of gas to leak until meter indicates $63 \%$ o maximum indication for the lear):

\section{Distribution}

Vacuum: Techs

Administrative Group, Div. Heads. 